\title{
Role of Anopheles stephensi Mosquitoes in Malaria Outbreak, Djibouti, 2019
}

Vincent Pommier de Santi, Bouh Abdi Khaireh, Thomas Chiniard, Bruno Pradines, Nicolas Taudon, Sébastien Larréché, Abdoulraouf Bourhan Mohamed, Franck de Laval, Franck Berger, Florian Gala, Madjid Mokrane, Nicolas Benoit, Lionel Malan, Abdoulilah Ahmed Abdi, Sébastien Briolant

Anopheles stephensi mosquitoes share urban breeding sites with Aedes aegypti and Culex quinquefasciatus mosquitoes in the Republic of Djibouti. We present evidence that $A$. stephensi mosquitoes might be responsible for an increase in malaria incidence in this country. We also document resistance of Plasmodium falciparum to dihydroartemisinin/piperaquine.

The Republic of Djibouti, bordered by Eritrea, EthiI opia, and Somalia, is a semiarid country in the Horn of Africa. The population comprises <900,000 persons, $70 \%$ of whom live in Djibouti, the capital city. Before 2013, malaria was hypoendemic to the country, with low levels of transmission in periruban and rural areas during December-May. Localized outbreaks occurred regularly, possibly caused by migration from surrounding countries. Most cases were caused by infection with Plasmodium falciparum

Author affiliations: Aix Marseille University, IRD, AP-HM, SSA, VITROME, Marseille, France (V. Pommier de Santi, B. Pradines, N. Benoit, S. Briolant); IHU-Méditerranée Infection, Marseille (V. Pommier de Santi, B. Pradines, N. Benoit, S. Briolant); French Armed Forces Center for Epidemiology and Public Health, Marseille (V. Pommier de Santi, F. de Laval, F. Berger, M. Mokrane); United Nations Development Program, The Global Fund to Fight AIDS, Tuberculosis and Malaria, Djibouti, Republic of Djibouti (B.A. Khaireh); French Armed Forces Medical Health Service, Djibouti (T. Chiniard, F. Gala, L. Malan); French Armed Forces Biomedical Research Institute, Marseille (B. Pradines, N. Taudon, N. Benoit, S. Briolant); National Center for Malaria, Marseille (B. Pradines, N. Benoit); Bégin Military Teaching Hospital, Paris, France (S. Larréché); Djiboutian Gendarmerie Health Service, Djibouti (A. Bourhan Mohamed); Aix Marseille University, INSERM, IRD, Sciences Economiques \& Sociales de la Santé \& Traitement de l'Information Médicale, Marseille (F. de Laval, F. Berger); Djiboutian Armed Forces Health Service, Djibouti (A. Ahmed Abdi)

DOI: https://doi.org/10.3201/eid2706.204557
(>80\%) or P. vivax. Before 2013, researchers considered the Anopheles arabiensis mosquito to be the primary vector (1).

The incidence of malaria had drastically decreased in the country since 2008; by 2012, this transmission level was compatible with preelimination goals (2,3). In 2013, an autochthonous outbreak of malaria occurred in Djibouti; field entomologic investigations identified An. stephensi mosquitoes as a new malaria vector (4). This species, a known vector of urban malaria in India and the Arabian Peninsula, has changed the epidemiologic profile of malaria in Djibouti (5). In 2018, malaria incidence increased to 25,319 confirmed cases $(64 \%$ caused by $P$. falciparum and $36 \%$ by $P$. vivax) and $>100,000$ suspected cases (Appendix Figure 1, https://wwwnc.cdc.gov/EID/ article/27/6/20-4557-App1.pdf).

The French Armed Forces (FAF) have served in Djibouti for decades. Service members and their families $(\approx 2,700$ persons) live in the capital. Despite malaria prevention and treatment measures described elsewhere (6), an outbreak among French military personnel occurred in February 2019; failure of early artemisinin combined therapy was documented in 1 patient.

\section{The Study}

We collated FAF epidemiologic surveillance data on malaria cases among service members in Djibouti during 1993-2019; the 2019 data included cases among family members. We defined a malaria case as an illness resulting in a positive result on a rapid diagnostic test or thin blood smear.

We conducted the field investigation in the capital during February 28-March 22, 2019. We obtained a dried blood spot on filter paper from each patient and stored the samples in a sealed plastic pouch until processing. We extracted DNA from the samples and 
confirmed diagnosis using PCR. We sequenced the antimalarial drug resistance molecular markers Pfdhfr, Pfmdr1, Pfcrt, and the propeller domain of PfK13 as described elsewhere (7). We treated patients with a 3-day regimen of dihydroartemisinin/piperaquine and measured levels of parasitemia on days 0 and 3; this treatment failed in 1 patient with malaria caused by P. falciparum. As follow-up for this patient, we collected blood samples from that patient on day 8 to determine piperaquine concentration using liquid chromatographic-tandem mass spectrometry.

We collected adult mosquitoes using human landing catches, CDC light traps, and BG-Sentinel and Suna traps (Biogents, https://www.biogents. com) (Table). We conducted larval prospecting in pools of water in French military camps, Djiboutian military police locations, and the Ambouli Gardens (a public area with a garden market and cattle breeding range). We reared larvae until imago emergence, then identified adult mosquitoes using a morphologic key (Walter Reed Biosystematics Unit, http://vectormap.si.edu/downloads/VHazard

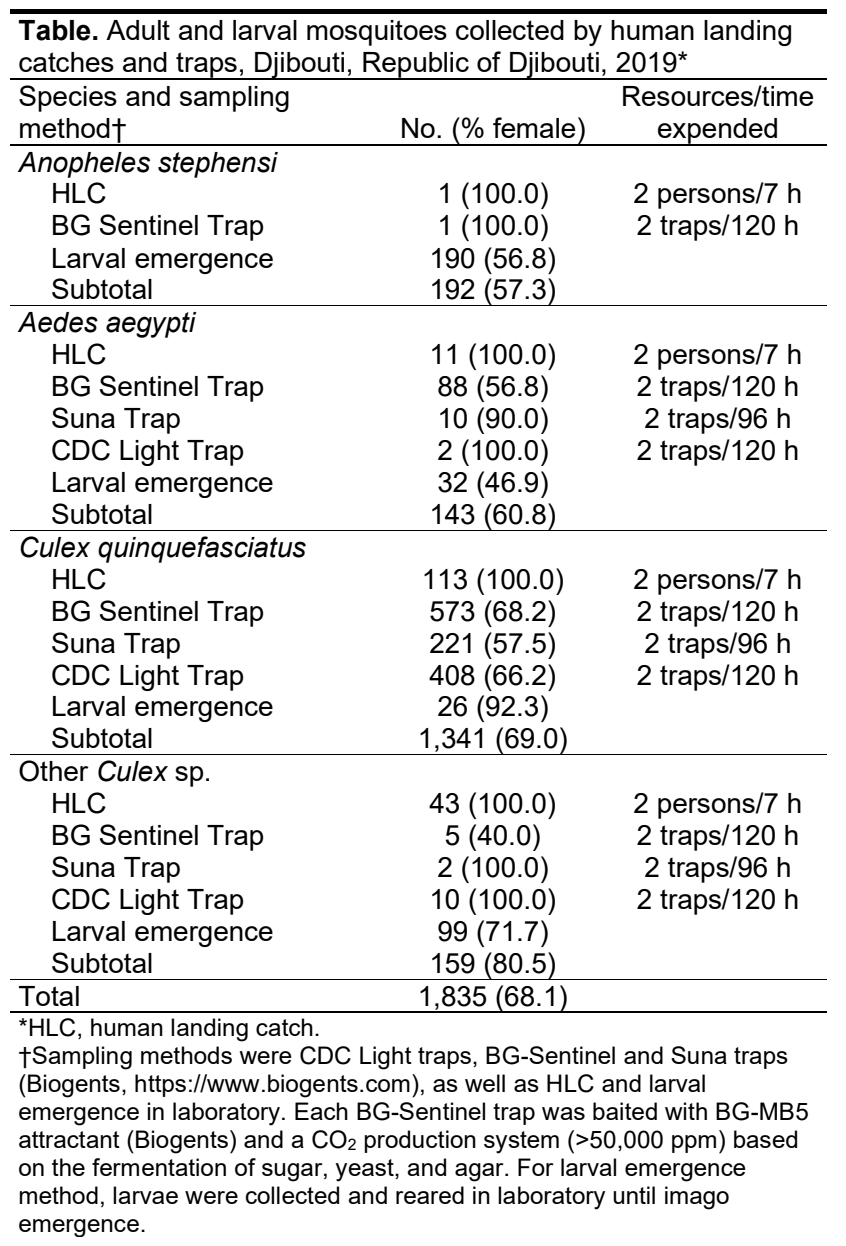

Reports/VHR_Anopheles_stephensi_2018.pdf). We extracted DNA from the legs of 103 An. stephensi mosquitoes and sequenced the cytochrome oxidase $\mathrm{C}$ subunit I gene to confirm morphologic identification. In addition, we conducted a phylogenetic analysis (Appendix Figure 2).

In the early 2000s, malaria incidence in the FAF was only 1-4 cases per year; during 2011-2013, no cases were documented (Figure 1). Malaria reemerged in 2014 and reached an incidence of 5.9 cases/1,000 persons in 2018 and 8.1 cases/1,000 persons in 2019. In the 2018-19 season, $P$. falciparum and $P$. vivax cocirculated (P. falciparum caused 20/38 [53\%] cases, $P$. vivax caused $17 / 38$ [45\%] cases, and P. ovale caused $1[2 \%]$ case). Among the country's population, incidence increased from 25.5 cases $/ 1,000$ persons in 2018 to 49.8 cases/1,000 persons in 2019 (Appendix Figure 1) (8). In 2019, we documented 1 instance of treatment failure in a FAF service member with $P$. falciparum infection; this patient had a thin blood smear showing a parasitemia level of $2.0 \%$. After 3 days of treatment with dihydroartemisinin/piperaquine, the patient still had a fever and $2.0 \%$ parasitemia level. The piperaquine plasma concentration on day 8 was $77.7 \mathrm{ng} / \mathrm{mL}$, above the therapeutic threshold (38.1 $\mathrm{ng} / \mathrm{mL}$ [95\% CI 25.8-59.3] expected on day 7), confirming good regimen adherence and absorption (9). This case met the definition for early treatment failure of an artemisinin derivative according to criteria from the World Health Organization (https://apps.who. int/iris/handle/10665/162441). We sequenced molecular markers of resistance to antimalarial drugs for 9 P. falciparum isolates (Appendix Table 3). All isolates had molecular markers associated with resistance to mefloquine. In addition, $89 \%$ had resistance markers against chloroquine and pyrimethamine or proguanil. We did not observe any mutations in the K13 propeller region (which sometimes contains mutations associated with artemisinin resistance), including the isolate from the patient in whom treatment failed (10). In Africa, failures of artemisinin combined therapy potentially caused by K13 mutations observed in Southeast Asia remain rarely described (11).

We conducted entomologic investigations during a dry period (i.e., February-March). We collected 1,835 adult mosquitoes and larvae: 1,500 Culex, 143 Aedes aegypti, and 192 An. stephensi (Table). We caught 2 adult An. stephensi mosquitoes using the human landing catch and BG-Sentinel trap. We identified 25 breeding sites, 15 of which contained An. stephensi larvae. All the An. stephensi breeding sites were artificial and located in urban or suburban areas; 9/15 also contained Ae. aegypti larvae, Cx. quinquefasciatus 


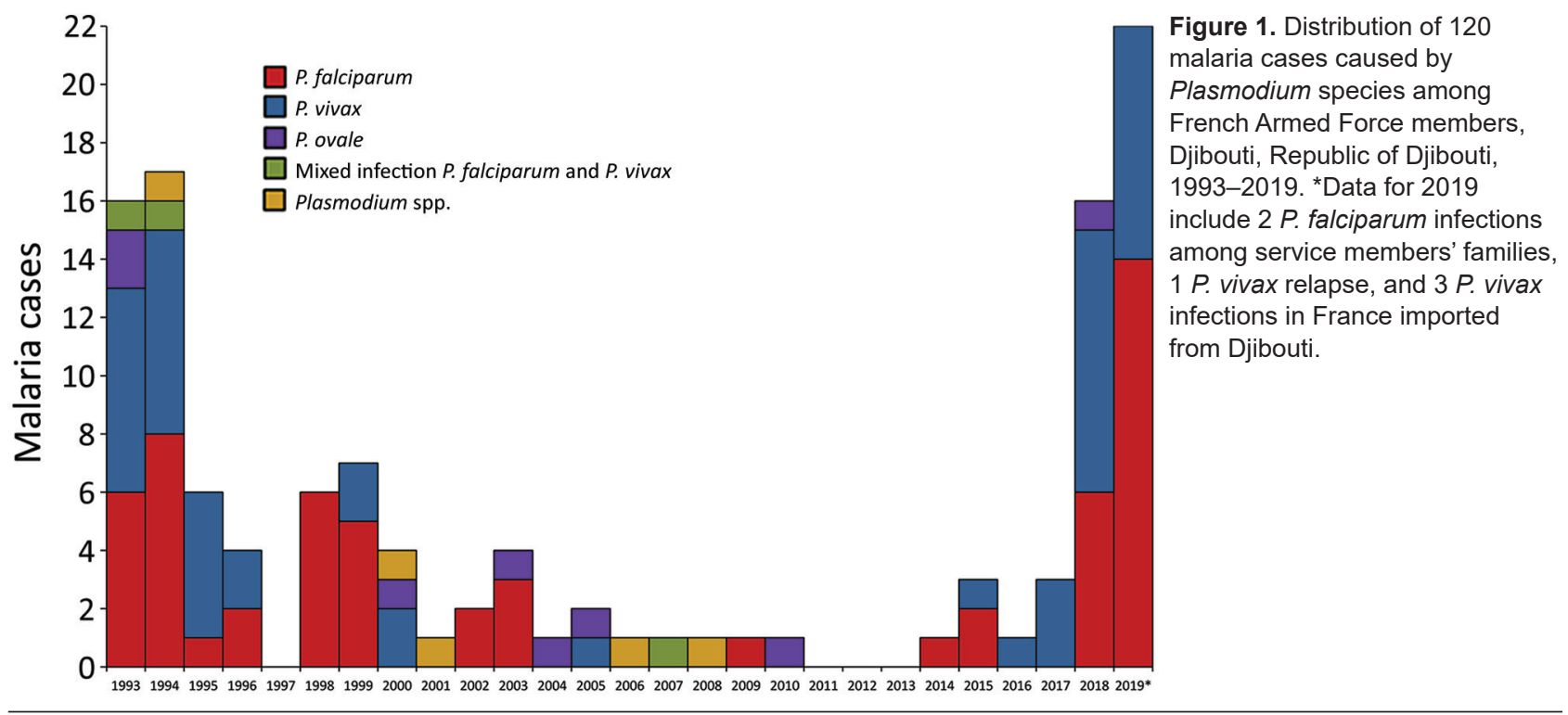

larvae, or both (Appendix Table 2). Examples of $A n$. stephensi breeding sites included manholes, ditches, plastic drums, and water tanks (Figure 2). In military camps, standing water was related to leaks and stagnation caused by faulty maintenance of the water distribution and drainage network. The most productive breeding sites $(\approx 800$ water tanks with thousands of An. stephensi larvae) were near livestock areas, mainly in the Ambouli Gardens district. We confirmed morphologic identification of adult An. stephensi mosquitoes by cytochrome oxidase $C$ subunit I sequencing, which identified 8 haplotypes. Phylogenetic trees did not clearly indicate the origin of An. stephensi mosquitoes in Djibouti (Appendix Figure 2).

\section{Conclusions}

In the Republic of Dibouti, malaria transmission has increased since 2013. Even populations with strong malaria control programs, such as the FAF, are now affected. In 2018, the country notified the World Health Organization of $\approx 100,000$ suspected cases, mainly among febrile patients with negative results on a rapid diagnostic test (Appendix Figure 1). Considering these suspected cases, we believe the true
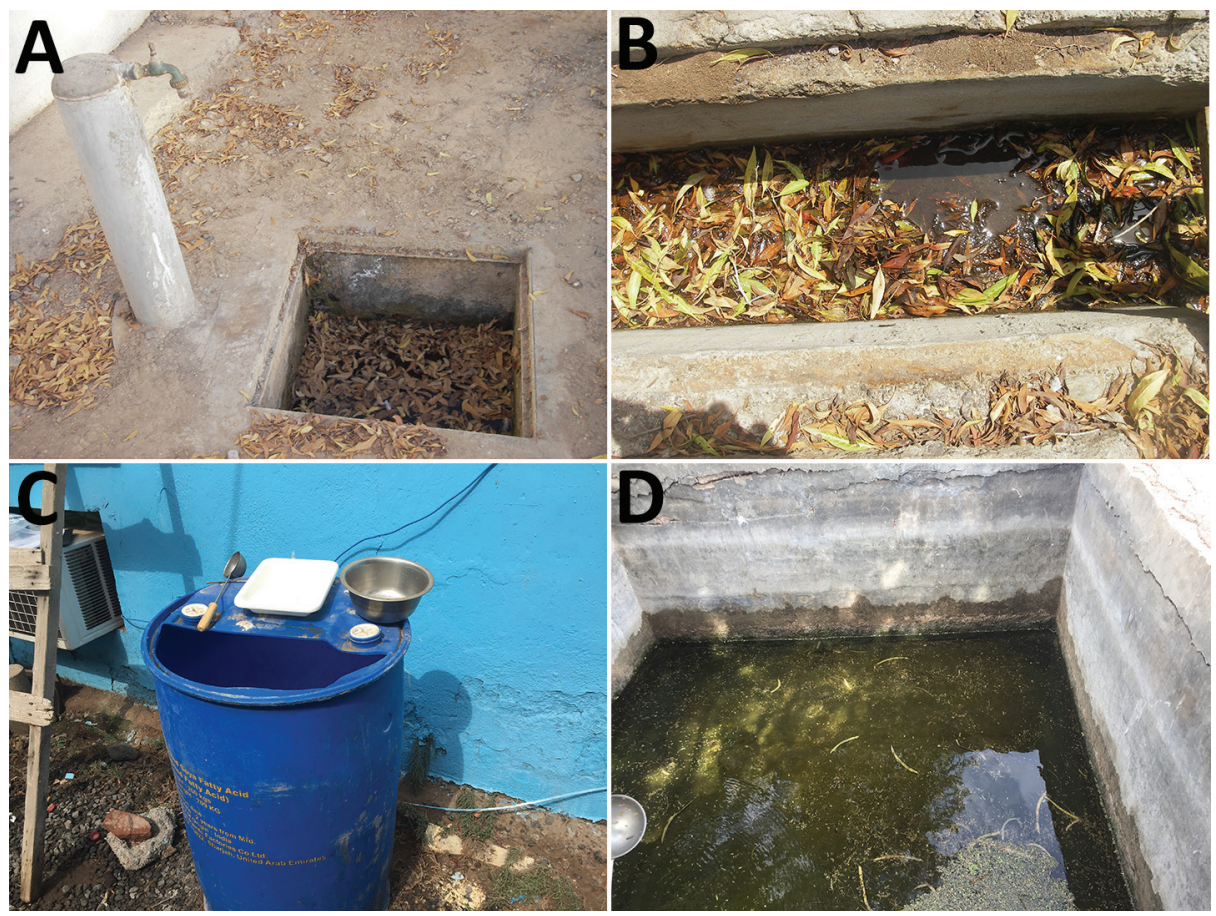

Figure 2. Anopheles stephensi breeding sites, Djibouti, Republic of Djibouti, 2019. A) Manhole. B) Ditch. C) Plastic drum. D) Water tank. 
incidence could be 5 times higher than the 25,319 cases confirmed that year. A recent study (12) found a high prevalence $(86.5 \%)$ of $p f h r p 2$ and $p$ fhrp3 gene deletion among $P$. falciparum parasites in the city of Djibouti.

We documented an early treatment failure of dihydroartemisinin/piperaquine in an isolate lacking a K13 mutation. This finding could signal the emergence of $P$. falciparum resistance to artemisinin derivatives in Djibouti.

An. stephensi mosquitoes are well-established in Djibouti and have been observed in Sudan and Ethiopia (13). Our study shows that this species shares breeding sites with Ae. aegypti and $C x$. quinquefasciatus mosquitoes, highlighting its adaptation to urban areas. Models predict broad expansion of An. stephensi mosquito distribution into major cities in Africa, where large malaria outbreaks could occur among growing resident populations susceptible to the disease (14). Furthermore, a high level of resistance among mosquitoes to all insecticide families (e.g., organochlorates, pyrethroids, carbamates, and organophosphates) has been described in Djibouti and Ethiopia $(8,15)$. In semiarid regions such as the Republic of Djibouti, residents often store water in plastic drums that act as breeding sites for An. stephensi mosquitoes. To control malaria and limit the spread of this anopheline species, communities and governments should prioritize larval control and access to the water distribution network.

\section{About the Author}

Dr. Pommier de Santi is a military physician and specialist in public health and epidemiology at the French Armed Forces Center for Epidemiology and Public Health, Marseille, France. His research interests include vectorborne diseases and other tropical diseases affecting the French Armed Forces and travelers.

\section{References}

1. Khaireh BA, Assefa A, Guessod HH, Basco LK, Khaireh MA, Pascual A, et al. Population genetics analysis during the elimination process of Plasmodium falciparum in Djibouti. Malar J. 2013;12:201. https://doi.org/10.1186/1475-2875-12-201

2. World Health Organization. World malaria report 2019. 2019 [cited 2020 Oct 21]. https://apps.who.int/iris/rest/ bitstreams/1262394/retrieve

3. Ollivier L, Nevin RL, Darar HY, Bougère J, Saleh M, Gidenne S, et al. Malaria in the Republic of Djibouti, 1998-2009. Am J Trop Med Hyg. 2011;85:554-9. https://doi.org/10.4269/ajtmh.2011.11-0122

4. Faulde MK, Rueda LM, Khaireh BA. First record of the Asian malaria vector Anopheles stephensi and its possible role in the resurgence of malaria in Djibouti, Horn of Africa. Acta
Trop. 2014;139:39-43. https:/ / doi.org/10.1016/j.actatropica.2014.06.016

5. Seyfarth M, Khaireh BA, Abdi AA, Bouh SM, Faulde MK. Five years following first detection of Anopheles stephensi (Diptera: Culicidae) in Djibouti, Horn of Africa: populations established - malaria emerging. Parasitol Res. 2019;118:72532. https://doi.org/10.1007/s00436-019-06213-0

6. Migliani R, Pradines B, Michel R, Aoun O, Dia A, Deparis $X$, et al. Malaria control strategies in French Armed Forces. Travel Med Infect Dis. 2014;12:307-17. https://doi.org/10.1016/j.tmaid.2014.05.008

7. Voumbo-Matoumona DF, Akiana J, Madamet M, Kouna LC, Lekana-Douki JB, Pradines B. High prevalence of Plasmodium falciparum antimalarial drug resistance markers in isolates from asymptomatic patients from the Republic of the Congo between 2010 and 2015. J Glob Antimicrob Resist. 2018;14:277-83. https:/ / doi.org/10.1016/j.jgar. 2018.08.003

8. Djibouti Ministry of Health. National strategic plan to fight malaria, 2020-2024 [in French]. 2020 [cited 2020 Oct 22]. https://erc.undp.org/evaluation/managementresponses/ keyaction/documents/download/3685

9. Hoglund RM, Workman L, Edstein MD, Thanh NX, Quang NN, Zongo I, et al. Population pharmacokinetic properties of piperaquine in Falciparum malaria: an individual participant data meta-analysis. PLoS Med. 2017;14:e1002212. https:// doi.org/10.1371/journal. pmed.1002212

10. Ariey F, Witkowski B, Amaratunga C, Beghain J, Langlois AC, Khim N, et al. A molecular marker of artemisinin-resistant Plasmodium falciparum malaria. Nature. 2014;505:50-5. https:// doi.org/10.1038/nature12876

11. Foguim Tsombeng F, Gendrot M, Robert MG, Madamet M, Pradines B. Are $k 13$ and plasmepsin II genes, involved in Plasmodium falciparum resistance to artemisinin derivatives and piperaquine in Southeast Asia, reliable to monitor resistance surveillance in Africa? Malar J. 2019;18:285. https://doi.org/10.1186/s12936-019-2916-6

12. Iriart X, Menard S, Chauvin P, Mohamed HS, Charpentier E, Mohamed MA, et al. Misdiagnosis of imported falciparum malaria from African areas due to an increased prevalence of $p f h r p 2 / p f h r p 3$ gene deletion: the Djibouti case. Emerg Microbes Infect. 2020;9:1984-7. https://doi.org/10.1080/ 22221751.2020.1815590

13. Balkew M, Mumba P, Dengela D, Yohannes G, Getachew D, Yared S, et al. Geographical distribution of Anopheles stephensi in eastern Ethiopia. Parasit Vectors. 2020;13:35. https:/ / doi.org/10.1186/s13071-020-3904-y

14. Sinka ME, Pironon S, Massey NC, Longbottom J, Hemingway J, Moyes CL, et al. A new malaria vector in Africa: predicting the expansion range of Anopheles stephensi and identifying the urban populations at risk. Proc Natl Acad Sci U S A. 2020;117:24900-8. https://doi.org/10.1073/ pnas. 2003976117

15. Yared S, Gebressielasie A, Damodaran L, Bonnell V, Lopez K, Janies D, et al. Insecticide resistance in Anopheles stephensi in Somali Region, eastern Ethiopia. Malar J. 2020;19:180. https:/ / doi.org/10.1186/s12936-020-03252-2

Address for correspondence: Vincent Pommier de Santi, Centre d'épidémiologie et de santé publique des armées, GSBdD Marseille Aubagne-CESPA - BP 40029, Marseille 13568, France; email: v.pommierdesanti@gmail.com 